\title{
The role of creatinine and histidine in Benedict's qualitative test for reducing sugar in urine
}

\author{
B. K. SUR, R. K. SHUKLA, AND V. S. AGASHE \\ From the Department of Biochenistry, GSVM Medical College, Kanpur, India
}

SYNOPSIS The statement made in some standard textbooks that Benedict's qualitative test gives a $\overrightarrow{\vec{\omega}}$ green, yellow, or orange-red precipitate with pure solutions of glucose of varying strength has been $\stackrel{\omega}{\omega}$ shown to be incorrect. Pure solutions of glucose give only a bright red precipitate at all concentrations. $\frac{\overline{0}}{0}$ These changes in the colour of the suspensions are observed with urinary glucose only.

The difference in the action of glucose in water and in urine has been shown to be mostly due to $\stackrel{\text { or }}{\rightarrow}$ creatinine and to a small extent to the histidine content of urine. The colour of the precipitate ${ }_{\infty}^{\circ}$ depends not only on the concentration of glucose but also on that of creatinine. An increase in $\stackrel{\cup}{N}$ concentration of creatinine tends to make the precipitate more yellow. Histidine has a similar though음 much smaller effect. Attention has been drawn to possible errors in the semi-quantitative assay of urinary glucose by Benedict's test arising out of variation in concentration of creatinine and histidine.

The formation of green, yellow, orange, or brick-red precipitate in Benedict's qualitative test is made the basis for a semi-quantitative assay of $0.5,1 \cdot 0,1 \cdot 5$, and $2 \%$ sugar in urine (Wootton, 1964). This test fails to distinguish urine samples of $2 \%$ and higher strengths of glucose as the colour of the precipitate is uniformly red and cannot be differentiated. At the request of some severely diabetic patients living out of easy reach of any pathology laboratory, an attempt was made to extend the use of Benedict's test to high-sugar urine. It was felt that this could be done if instead of red, a green or yellow precipitate could be produced by using only 1 or 2 drops of urine instead of the usual 8 drops. Thus 1 drop of a specimen with $4 \%$ glucose being equivalent to 8 drops of urine with $0.5 \%$ glucose should give a green turbidity. It was observed that the precipitate was always red. Green or yellow precipitate did not form however small the quantity of urine tested. It was puzzling to find that if after adding 1 or 2 drops of the test sample, further drops of normal urine were added to make up the usual 8 drops before beginning the test, green or yellow turbidity appeared. The Benedict's qualitative test was therefore investigated iurther.

Statements made in some widely read textbooks (Oser, 1965; Harper, 1969) clearly imply that green, yellow, orange, and brick-red precipitates of cuprous oxide are obtained if pure solutions of glucose of Received for publication 17 August 1972. varying concentration are tested. Preliminary ex- $-\vec{\theta}$ periments showed, however, that pure solutions $8 \mathrm{f}$ ! glucose of different strengths always yield a prê-: cipitate of a bright red colour whereas solutions glucose in normal urine yield turbidity of varying colours. There are therefore one or more urinary constituents which alter the colour of the red $\stackrel{\square}{\perp}$ precipitate of cuprous oxide formed during Bene- $\vec{F}$ dict's qualitative test. Results of experiments made 3 to identify these constituents are presented.

\section{Material and Methods}

Benedict's qualitative test was carried out by mixing $0.4 \mathrm{ml}$ of test solution in $5 \mathrm{ml}$ of Benedict's qualitative reagent prepared from Analar chemicals in test tubeso of $16 \mathrm{~mm}$ internal diameter. The test tubes were covered with a marble and immersed in a boiling? water bath for five minutes and allowed to cool at $>$ room temperature. The turbid solution was mixed을. and its colour noted. The colour of the precipitaten was observed after it slowly settled down or after centrifugation.

The effect of urinary constituents, at a concentra $-N_{\omega}$ tion corresponding to that in normal urine witho added glucose $(0.5 \%)$, on the colour of the cuprouso oxide precipitate was studied first singly and then in combination as there could be mutual interaction $\stackrel{\circ}{+}$ of the urinary constituents. The influence of in- 0 creasing concentration of creatinine on the colour 
of the precipitate at various concentrations of glucose was also studied.

\section{Results}

The results obtained are presented in Tables I and II and Figure 1.

It would appear from Table I that care must be taken in describing the colour of cuprous oxide precipitate formed during Benedict's qualitative sugar test. It is frequently confused with the overall colour of the precipitate and the blue colour of Benedict's solution. Thus the description of formation of a green precipitate (Oser, 1965; Harper, 1969 ) is a common error. While the precipitate is actually pure yellow, the blue background of the solution imparts an overall green colour to the turbid suspension. In the same way, although the suspension appears brown with $1 \%$ glucose in water, the colour of the precipitate after settling is actually bright red. Table I shows that variation in concentration of glucose in water does not result in any change in the colour of the cuprous oxide precipitate which is uniformly of a bright red colour. This shows that the statements made in standard textbooks (Oser, 1965; Harper, 1969) regarding the appearance of green, yellow, orange, and red, or brick-red precipitate with pure solutions of glucose of varying strength are incorrect. When glucose was added to normal urine and then tested, turbid suspensions appearing green, greenish yellow, yellow, orangish yellow, and yellowish orange were obtained. The actual colour of the precipitate obtained in the present investigation was never green but yellow, orangish yellow, or yellowish orange. It can be inferred, therefore, that one or more constituents of urine modify the colour of red cuprous oxide precipitate to yellow or yellowish orange.

It is clear from Table II that urea, phosphate, bicarbonate, chloride, sulphate, $\mathrm{Na}^{+}, \mathrm{K}^{+}, \mathrm{Ca}^{++}$, and $\mathrm{NH}_{4}{ }^{+}$when mixed in amounts present in normal urine did not alter the red colour of the cuprous oxide precipitate. Uric acid, which may have a slight

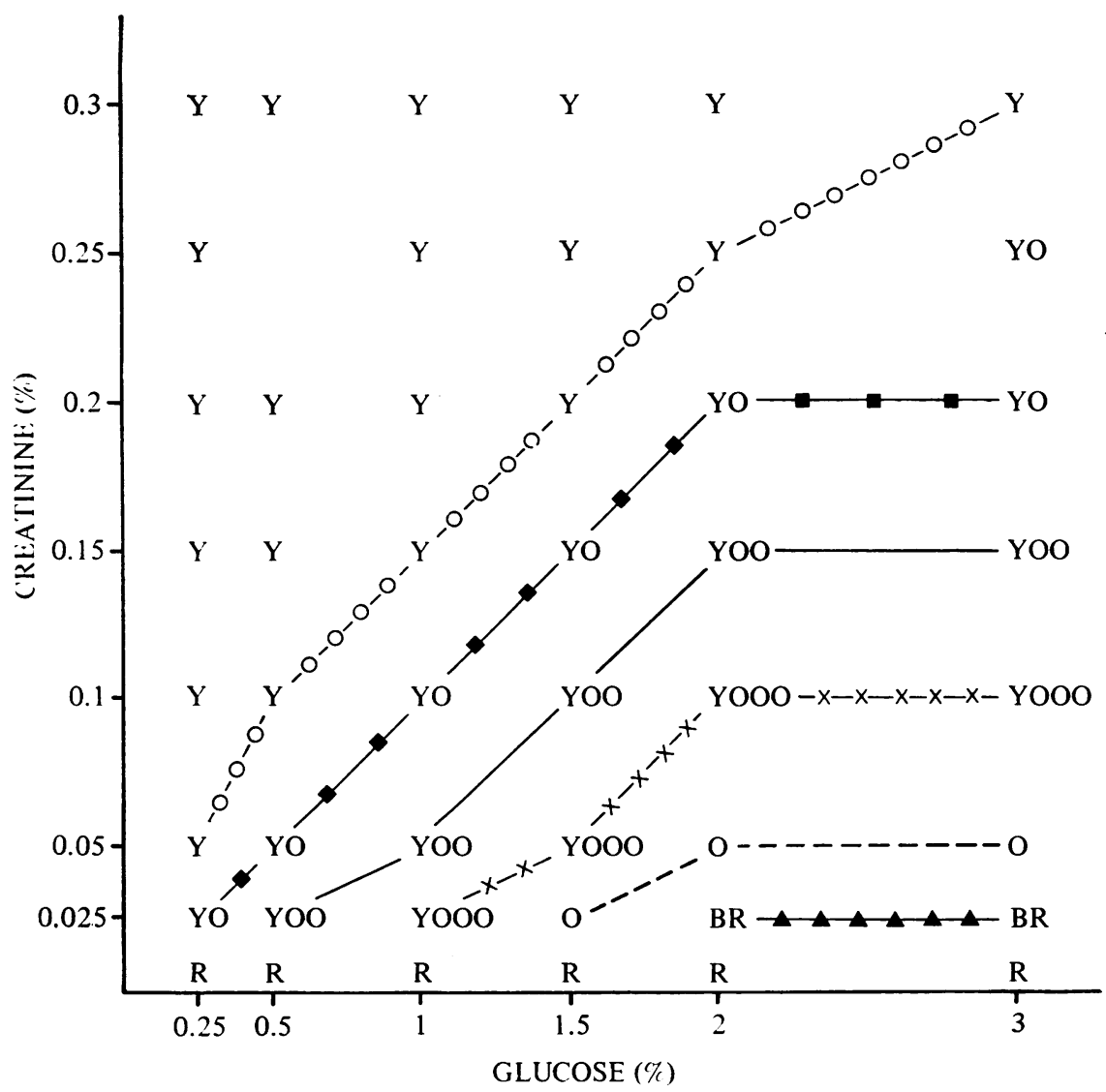

Fig. Influence of variation of strength of creatinine solution at different concentrations of glucose on colour of cuprous oxide precipitate. $\mathrm{Y}=$ yellow; YO, YOO, YOOO = yellow with increasing tinge of orange; $\mathrm{O}=$ orange; $\mathrm{BR}=$ brick-red, and $R=$ bright red 


\begin{tabular}{|c|c|c|c|c|}
\hline \multirow[t]{2}{*}{ Glucose (\%) } & \multicolumn{2}{|c|}{ Colour of Suspension just after Boiling } & \multicolumn{2}{|c|}{ Colour of Precipitate after Settling } \\
\hline & Glucose in Water & Glucose in Urine & Glucose in Water & Glucose in Urine \\
\hline $0 \cdot 1$ & $\begin{array}{l}\text { Blue solution, no visible } \\
\text { precipitate }\end{array}$ & Green, precipitate not visible & Bright red (trace precipitate) & $\begin{array}{r}\text { Yellow (trace } \\
\text { precipitate) }\end{array}$ \\
\hline 0.5 & Brownish blue & Green & Bright red & Yellow \\
\hline $1 \cdot 0$ & Brown & Greenish yellow & Bright red & Yellow \\
\hline $1 \cdot 5$ & Brownish red & Yellow & Bright red & Yellow \\
\hline $2 \cdot 0$ & Red & Orangish yellow & Bright red & Orangish yellow \\
\hline 3.0 & Bright red & Yellowish orange & Bright red & Yellowish orange \\
\hline
\end{tabular}

Table I Influence of normal urine on the colour of cuprous oxide precipitate formed during Benedict's qualitative sugar test

\begin{tabular}{|c|c|c|}
\hline \multirow[t]{2}{*}{ Specimen Tested } & \multicolumn{2}{|l|}{ Colour of } \\
\hline & $\begin{array}{l}\text { Turbid } \\
\text { Suspension }\end{array}$ & $\begin{array}{l}\text { Centrifuged } \\
\text { Precipitare }\end{array}$ \\
\hline $\begin{array}{l}\text { Normal urine } \\
\text { Synthetic urine } \text { (SU) }^{1} \text { SU + uric a cid, } 0 \cdot 07 \% \\
\text { SU + ascorbic acid, } 0 \cdot 5 \% \\
\text { SU + amino a cids } \\
\text { SU + histidine, } 0 \cdot 06 \% \\
\text { SU + creatinine, } 0 \cdot 1 \% \\
\text { SU + creatine, } 0 \cdot 04 \%\end{array}$ & $\begin{array}{l}\text { Brownish blue } \\
\text { Brownish blue } \\
\text { Brownish blue } \\
\text { Brownish blue } \\
\text { Brownish blue } \\
\text { Green } \\
\text { Green } \\
\text { Brownish blue }\end{array}$ & $\begin{array}{l}\text { Bright red } \\
\text { Bright red } \\
\text { Bright red } \\
\text { Bright red } \\
\text { Bright red } \\
\text { Orange } \\
\text { Yellow } \\
\text { Bright red }\end{array}$ \\
\hline
\end{tabular}

Table II Effect of urinary constituents on the colour of the cuprous oxide precipitate in Benedict's qualitative test

All specimens had 0.5\% glucose.

${ }^{1} \mathrm{KH}_{2} \mathrm{PO}, 435 \mathrm{mg}, \mathrm{Na}, \mathrm{HPO}, 25 \mathrm{mg}, \mathrm{NaHCO}_{3} 18 \mathrm{mg}, \mathrm{NaCl} 1400 \mathrm{mg}$, $\mathrm{KHSO}_{4} 380 \mathrm{mg}, \mathrm{CaCl}_{2} 2 \mathrm{H}_{2} \mathrm{O} 75 \mathrm{mg}, \mathrm{NH}_{4} \mathrm{Cl} 220 \mathrm{mg}$, and urea 2000 $\mathrm{mg} / 100 \mathrm{ml}$ water.

$20.01 \%$ of alanine, arginine, cystine, leucine, lysine, methionine, serine, tyrosine, and valine, and $0.06 \%$ of glycine, glutamic acid, and taurine were each tested separately.

reducing effect on Benedict's solution (Harrison, 1957; Frankel, 1963), and ascorbic acid, well known as a strong reducing substance, had no effect on the red colour of the precipitate. Of the 13 amino acids tested, histidine alone changed the colour of the cuprous oxide precipitate to orange. Creatinine, however, completely altered the colour of the precipitate to yellow. Creatinine is the anhydride of creatine and as such the latter may be expected to modify the colour of the precipitate in the way creatinine does. Surprisingly, creatine did not show any such effect. It appears therefore that of all the urinary constituents, only creatine and histidine alter the colour of the cuprous oxide precipitate.

In a separate experiment, it was observed that on a molar basis creatinine is about ten times more effective than histidine in modifying the colour of the precipitate. As the urinary excretion of histidine is much less than that of creatinine, it may be concluded that creatinine is mostly responsible for changing the colour of the precipitate. However, since the excretion of histidine increases considerably during pregnancy (Bigwood, Crokaert, Schram,
Soupart, and Vis, 1959), its effect may be appreciable $\vec{\omega}$ in this condition.

Figure 1 shows that the colour of the cuprous? oxide precipitate is dependent on the relative con- $N$ centration of glucose and creatinine. In the absence $\vec{D}$ of creatinine, the colour is bright red whereas in the $\%$ presence of $0.3 \%$ creatinine, the colour is yellow at $\mathrm{N}$ all concentrations of glucose. At low concentrations응 of glucose a yellow precipitate is obtained if the creatinine/glucose ratio is $1 / 5$ or greater. As the $O$ proportion of creatinine decreases the intermediate $\frac{?}{0}$ shades with increasing red are obtained. Glucose is likely to be underestimated in urine with high creatinine and high glucose and overestimated in $\vec{\varphi}$ urine with low creatinine and low glucose.

In recent years the entrenched belief in the constancy of 24-hour excretion of urinary creatinine for any one individual has been shown to be in- $\vec{\partial}$ correct (Edwards, Bayliss, and Millen, 1969; Zorab, Clark, and Harrison, 1969; Pierro and Johnson, $\stackrel{\odot}{\circ}$ 1970). Day-to-day variation in the 24-hour urinary $\Rightarrow$ creatinine of an individual can be quite large. Much $\frac{3}{3}$ greater would be the fluctuation in the concentration of urinary creatinine of an individual, owing largelye to the variation in volume of urine and to a lesser extent to the ingestion of preformed creatinine in the form of fish and meat. It would decrease during the polyurea of diabetes mellitus, in cold and humid $\stackrel{3}{\text {. }}$. weather, and on taking diuretics. The concentration 0 of creatinine would increase in hot, dry weather, in

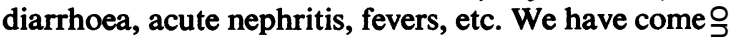
across high-creatinine urine with $4 \%$ glucose which $\supset$ gave a yellow precipitate and had been assayed as urine with $1 \%$ sugar, and low-creatinine urine with $1 \%$ glucose which gave a brick-red precipitate and ${ }^{\circ}$ could be mistaken as urine with $2 \%$ glucose or more. $N$

In order not to make this type of error, it is necessary to observe the bulk of the precipitate in addition to its colour, and, better still, to observe the extent of the bluish tinge in the supernatant after $\frac{C}{\Phi}$ the precipitate has settled. If there is no bluish tinge? in the supernatant the urine must have at least $3 \%$ ㅁ glucose even if the colour of the precipitate is yellow 
indicating $1 \%$ sugar. Similarly a brick-red precipitate with a fairly strong blue supernatant would indicate $1 \%$ glucose and not $2 \%$ or more sugar. The optical density of the blue supernatant can be used for an accurate estimation of urinary glucose irrespective of creatinine content (Sur, Shukla, and Agashe, 1972).

The influence of creatinine on the colour of cuprous oxide precipitate explains why it is not possible to obtain greenish or yellowish suspensions with one or two drops of high-glucose urine as the small sample has very little creatinine. It also explains why one or two drops of high-sugar urine can be used for a semi-quantitative assay together with additional drops of normal urine which provides creatinine in sufficient quantity.

Incidentally, the present work can be adapted for a qualitative test of creatinine in solution. If $0.5 \%$ glucose and the given solution form a yellow precipitate on testing with Benedict's reagent, the test solution may contain creatinine. If a red precipitate is formed, the solution is devoid of creatinine.
We are grateful to $\mathrm{Dr}$ G. Sur for valuable suggestions in the course of this work.

\section{References}

Bigwood, E. J., Crokaert, R., Schram, E., Soupart, P., and Vis, H. (1959). Amino aciduria. Advance. clin. Chem., 2, 201-265.

Edwards, O. M., Bayliss, R. I. S., and Millen, S. (1969). Urinary creatinine excretion as an index of the completeness of 24 hour urine collections. Lancet, 2, 1965-66.

Frankel, S. (1963). Urine analysis: chemical examination. In Gradwohl's Clinical Laboratory Methods and Diagnosis, 6th ed., vol. 2, edited by S. Frankel and S. Reitman. Mosby, St Louis.

Harper, H. A. (1969). Review of Physiological Chemistry, 12th ed., p. 11. Lange, Los Altos, California.

Harrison, G. A. (1957). Chemical Methods in Clinical Medicine, 4th ed., p. 160. Churchill, London.

Oser, B. L. (Ed.) (1965). Hawk's Physiological Chemistry, 14th ed., p. 83. McGraw Hill, New York.

Pierro, A., and Johnson, R. E. (1970). Creatinine excretion. Lancet, 1,784

Sur, B. K., Shukla, R. K., and Agashe, V. S. (1972). Mode of action of creatinine on colour of cuprous oxide precipitate in Benedict's qualitative sugar test. J. clin. Path., 25, 896-898.

Wootton, I. D. P. (1964). Micro-Analysis in Medical Biochemistry, 4th ed., p. 161. Churchill, London.

Zorab, P. A., Clark, S., and Harrison, A. (1969). Creatinine excretion. Lancet, 2, 1254. 